\title{
Focal Expression of Interleukin-2 Does Not Break Unresponsiveness to "Self" (Viral) Antigen Expressed in $\beta$ Cells but Enhances Development of Autoimmune Disease (Diabetes) after Initiation of an Anti-Self Immune Response
}

\author{
Matthias G. von Herrath, * Janette Allison, ${ }^{*}$ Jacques F. A. P. Miller, ${ }^{*}$ and Michael B. A. Oldstone* \\ *Division of Virology, Department of Neuropharmacology, The Scripps Research Institute, La Jolla, California 92037; and ${ }^{\ddagger}$ Walter and \\ Eliza Hall Institute of Medical Research, Victoria, 3050 Australia
}

\begin{abstract}
The participation of IL-2 in insulin-dependent (type 1) diabetes (IDDM) was analyzed in transgenic ( $t g$ ) mice expressing the nucleoprotein (NP) of lymphocytic choriomeningitis virus and $I L-2$ under control of the rat insulin promoter focally in $\beta$ cells of the islets of Langerhans. Insertion and expression of the viral (self) gene or of the $\mathrm{CL-2}$ gene alone did not lead to IDDM. Infiltration primarily of CD4 and B lymphocytes and increased expression of MHC class I and II molecules occurred in islets where IL-2 was expressed. By contrast, neither cellular infiltrates nor expression of MHC class I or II glycoproteins above base levels was noted in tgs expressing the viral protein alone. Double tg mice expressing both the viral protein and $\mathrm{IL-2}$ in their islets displayed a modest increase in incidence of spontaneous diabetes compared with that of single transgenic mice expressing IL-2 alone. Breaking of immunological unresponsiveness or sensitization to self antigens did not occur. Neither cytotoxic T lymphocytes (CTL) nor antibodies directed against the viral tg (NP) were generated. However, after challenge with lymphocytic choriomeningitis virus, double tg mice developed anti-self (viral) CTL and IDDM (incidence $>95 \%$ ) within 2 mo. The generation of virus ("self")-specific MHC-restricted CTL was dependent on $\mathrm{CD4}^{+}$help. In contrast, viral inoculum to single tg mice expressing either the viral protein or $\mathrm{IL}-2$ failed to enhance the incidence of IDDM over $30 \%$ for viral protein or $10 \%$ for IL-2 after an 8-mo observation period. Hence, in this autoimmune model in situ expression of $\mathrm{IL-2}$ did not break unresponsiveness but markedly enhanced ongoing disease. (J. Clin. Invest. 1995. 95:477-485.) Key words: interleukin2 - autoimmune diabetes - lymphocytic choriomeningitis virus - cytotoxic $\mathrm{T}$ lymphocytes $\cdot \mathrm{CD}^{+}$help
\end{abstract}

\section{Introduction}

Destruction of the insulin-producing $\beta$ cells located in the islets of Langerhans leads to insulin-dependent diabetes mellitus

Address correspondence to Dr. Michael B. A. Oldstone, Division of Virology, Department of Neuropharmacology, The Scripps Research Institute, 10666 N. Torrey Pines Road, La Jolla, CA 92037. Phone: 619554-8054; FAX: 619-554-9981.

Received for publication 15 July 1994 and in revised form 20 September 1994.

J. Clin. Invest.

(c) The American Society for Clinical Investigation, Inc. 0021-9738/95/02/0477/09 \$2.00

Volume 95, February 1995, 477-485
(IDDM). ${ }^{1}$ Host genes, $T$ cell autoimmune responses, cytokines, and viruses have all been implicated in the initiation and progression of this disease. We have created transgenic ( $\mathrm{tg}$ ) mouse models to allow a dissection of the potential role(s) of these various components $(1,2)$. Initially we showed (1) that tg mice expressing a viral ("self") nucleoprotein (NP) gene of lymphocytic choriomeningitis virus (LCMV) in pancreatic $\beta$ cells under control of the rat insulin promoter (RIP) fail to develop IDDM even over a 15-mo observation period. However, despite the presence of the viral gene since the egg stage these mice are not tolerant to the transgene, as upon exposure to LCMV > 95\% develop IDDM in 3-6 mo and all generate both an anti-viral (anti-self) $\mathrm{CD}^{+}$cytotoxic $\mathrm{T}$ lymphocyte (CTL) response and anti-viral antibodies. Later studies including adoptive transfer of $\mathrm{CD}^{+}$cells recovered from their islets, immunochemical depletion, and use of CD8 knockout mice indicate that these effector $T$ cells are responsible for the selective and progressive damage of pancreatic $\beta$ cells leading to $\operatorname{IDDM}(1,2)$.

Activation of naive $\mathrm{T}$ lymphocytes is a multifaceted process requiring binding of the T cell receptor to the appropriate $\mathrm{MHC} /$ peptide complex and costimulation with $\mathrm{B} 7$ or allogeneic spleenocytes ( 3 ) and cytokines. The cytokine IL-2 is the dominant cytokine produced in an autocrine fashion by naive $\mathrm{CD} 4^{+}$and $\mathrm{CD}^{+}$(CD45RO) $\mathrm{T}$ lymphocytes (4) and is required for their differentiation into CD8 ${ }^{+}$effector CTL (5) or $\mathrm{Th}_{1}$ and $\mathrm{Th}_{2}$ subsets of $\mathrm{CD}^{+}{ }^{+}$lymphocytes (6). Several in vitro studies have demonstrated IL-2's effect on Th1 CD4 ${ }^{+} \mathrm{T}$ lymphocytes including the reversal of immunological anergy (7). Further, IL-2 can activate non-MHC-restricted killer cells (8), tumor-infiltrating lymphocytes (9), and CTL (10-13). It also interferes with the maintenance of immunological tolerance in vivo. For example, IL-2 expressed focally in $\beta$ cells of transgenic mice can provide exogenous help to activate potentially autoreactive but silent $T$ cells and can cause IDDM in an allogeneic model (14). Furthermore, peripheral $\mathrm{T}$ cell tolerance in thymectomized mice (15) has been reversed by IL-2. In this model potentially autoreactive $T$ cells that escape thymic elimination persist in the periphery but become ignorant. These cells can be reactivated in vivo by high levels of IL-2 (16). Other studies in a chimeric human/SCID model have also demonstrated that IL-2 can reactivate unresponsive anti-self $\mathrm{T}$ lymphocytes (17).

To explore the potential role of IL-2 in breaking immunolog-

1. Abbreviations used in this paper: APC, antigen-presenting cell; CTL, cytotoxic T lymphocyte; IDDM, insulin-dependent diabetes mellitus; LCMV, lymphocytic choriomeningitis virus; NP, nucleoprotein; pfu, plaque forming unit; RIP, rat insulin promoter; tg, transgenic. 
ical ignorance to a viral transgene, we generated double tg mice that expressed the viral ("self") transgene and IL-2 focally in $\beta$ cells in the islets of Langerhans. This allowed us to address two questions. First, can IL-2 expressed in concert with a viral ("self") gene spontaneously activate an anti-viral CTL response and initiate IDDM? Second, does the focal expression of IL-2 potentiate the incidence of IDDM after infection with virus later in life? Results presented here indicate that the local expression of IL-2 is unable, per se, to break the unresponsive state (failure to generate anti-viral [self] $\mathrm{CD} 8^{+} \mathrm{CTL}$ ) to the viral transgene. Such double tg mice fail to develop IDDM despite the presence of infiltrating $\mathrm{CD}^{+}{ }^{+}$and $\mathrm{B}$ cells around islets and induction of MHC class I and II molecules on the surface of pancreatic $\beta$ cells. However, after infection with LCMV, IL- 2 markedly potentiates the incidence of IDDM. At this time, autoreactive $\mathrm{CD} 8^{+} \mathrm{CTL}$ to the viral (self) antigen occur and this response is dependent on $\mathrm{CD} 4{ }^{+} \mathrm{T}$ helper lymphocytes.

\section{Methods}

Transgenic mouse lines. The tg mouse line expressing the LCMV NP, NP 25-3, was generated in $\mathrm{H}-2^{\mathrm{b}}$ (C57B1/6) mice using the RIP vector and cDNA clone for LCMV NP $(1,18,19)$. Such mice express the transgene in the $\beta$ cells of the islets of Langerhans and thymus but not other tissues (2). These mice fail to display a mononuclear cellular infiltrate in or around the islets and do not develop IDDM unless challenged with LCMV (1). H-2 ${ }^{\mathrm{k}} \times \mathrm{H}-2^{\mathrm{b} / \mathrm{bml}}(\mathrm{CBA} \times \mathrm{B} 10 . \mathrm{BR})$ tg mice expressing IL-2 in $\beta$ cells through the use of the RIP were generated by Allison et al. (20). These mice display mononuclear cell infiltrates in and around their islets and have a spontaneous incidence of IDDM of $<10 \%$. Doubly $\operatorname{tg}$ mice that expressed both LCMV NP and IL-2 focally in their $\beta$ cells were made by mating $\mathrm{H}-2^{\mathrm{b}}$ RIP NP $25-3$ to RIP IL-2 mice. Progeny were bred five generations to the C57B1/6J $(\mathrm{H}-$ $2^{\text {b }}$ ) background, and expression of both LCMV NP and IL-2 transgenes was confirmed by PCR (2).

Virus. Virus used was LCMV Armstrong (ARM), clone 53b. Its origin, quantitation by plaquing, sequence, and biological properties have been described (21).

$C T L$ assay. CTL activity was recorded in a 5-6-h in vitro ${ }^{51} \mathrm{Cr}$ release assay (1). Samples were run in triplicate and variance was $<10 \%$. To judge CTL activity, uninfected or targets infected with either LCMV ARM (MOI 1) or vaccinia virus expressing LCMV NP or LCMV glycoprotein (GP) (MOI 3 ) were used. Target cells were $\mathrm{H}-2^{\mathrm{b}}$ (MC57), H-2 ${ }^{\mathrm{d}}$ (BALB C17), or $\mathrm{H}-2^{\mathrm{k}}$ fibroblasts. Lymphocytes from spleens of 8-12-wk-old unimmunized mice or mice inoculated $7 \mathrm{~d}$ earlier with $2 \times 10^{5}$ plaque forming units (pfu) of LCMV ARM intraperitoneally were used as effectors at 50:1,25:1, and 12:1 effector:target ratios, while $\mathrm{H}-2^{\mathrm{b}}$ and $\mathrm{H}-2^{\mathrm{d}}$ restricted LCMV specific CTL clones (2225) were used at effector:target ratios of 10:1, 5:1, and 1:1. Other secondary CTL lines and clones were generated and cloned by limiting dilution (26). For coating of target cells with peptides, target cells were preincubated with the respective peptide at $50 \mu \mathrm{g} /$ well $30 \mathrm{~min}$ before starting the incubation for the ${ }^{51} \mathrm{Cr}$ release assay.

Recovery of CTL from pancreas. CTL were isolated from pancreata as described (1). Briefly, tissue obtained from transgenic mice were freed from fat and lymphoid tissue. Collagenase digestion was carried out and lymphoid cells were purified through a Ficoll-Hypaque gradient.

Analysis of IDDM. IDDM was defined by hyperglycemia, low levels of pancreatic insulin, and a mononuclear infiltration in the islets. Blood samples were obtained from the retro-orbital plexus of mice at weekly or monthly intervals. Amount of glucose in the blood was determined using Accucheck II strips (Boehringer Mannheim, Indianapolis, IN). Mice with glucose values $>300 \mathrm{mg} / \mathrm{dl}$ were considered diabetic (normal blood glucose for age- and sex-matched control was mean $\pm 1 \mathrm{SE}$
[20-40 mice/group] $185 \pm 7$ ). Mice with values $>300 \mathrm{mg} / \mathrm{dl}$ were killed. Insulin concentration in the pancreas was determined by radioimmune assay (1). Levels of $10 \mu \mathrm{g}$ insulin or less per milligram of pancreatic tissue were considered abnormal, with normal levels of insulin being $50 \mu \mathrm{g} / \mathrm{mg} \pm 12$ (1). Absence or presence of mononuclear cells in the islets was studied in tissues fixed in $10 \%$ zinc formalin, mounted in paraffin, and stained with hematoxylin and eosin $(1,2)$.

Immunohistochemical analyses of tissues. Immunochemical studies were carried out on 6-10- $\mu \mathrm{m}$ cryomicrotome sections. Tissues were quick frozen in O.C.T. compound, and a $6-10-\mu \mathrm{m}$ section was obtained, fixed for $1 \mathrm{~min}$ in $1 \%$ paraformaldehyde, washed in PBS, and incubated with avidin/biotin to remove nonspecific binding. Primary antibodies were applied for $1 \mathrm{~h}$. These consisted of rat anti-mouse CD4 (clone RM 4-5), anti-CD8 (clone 53-6.7), anti-B220 (clone RA3 6B2), antiF4/80 (clone A3-1), anti-MAC-1 (clone M 1/70), anti-vascular cell adhesion molecule, anti-class I (clone M 1/42) and anti-class II (clone M5/114) (PharMingen, San Diego, CA, and Boehringer Mannheim), and mouse anti-LCMV antibody 1.1.3. A 1-h incubation with secondary antibody (biotinylated goat anti-rat [or anti-mouse] IgG [Vector Labs, Inc., Burlinghame, $\mathrm{CA}]$ ) followed. Color reaction was obtained after sequential treatment with avidin-horseradish peroxidase conjugate (Boehringer Mannheim) and diaminobenzidine/hydrogen peroxide (2).

Phenotyping and selective depletion of lymphocytes. Cultured lymphocytes were phenotyped by FACS ${ }^{\circ}$ using monoclonal antibodies to murine CD4 (rat monoclonal antibody YTS 191.1.1) and CD8 (rat monoclonal antibody YTS 169.4.2) (1). For depletion of $\mathrm{CD}^{+}$or $\mathrm{CD} 8{ }^{+} \mathrm{T}$ lymphocyte subsets, monoclonal rat anti-mouse antibodies 53 6-72 and GK 1.5 were used, respectively (2). Briefly, mice were injected intravenously with $1 \mathrm{mg} / 0.2 \mathrm{ml}$ of the appropriate antibody $2 \mathrm{~d}$ before and $4 \mathrm{~d}$ after LCMV infection. Depletion was confirmed by FACS ${ }^{\circ}$ analysis.

Biochemical studies. Mice carrying the LCMV transgenes were identified by hybridization of DNA extracted from tail biopsies using an LCMV-NP-specific probe (1). For RNA analysis, RNA was extracted from peripheral blood mononuclear cells and organs (thymus and pancreas) using the GTC method $(2,27)$. RIP IL-2 mice were screened by PCR technique (27). The PCR was run for 40 cycles and products were analyzed on a $3 \%$ agarose gel. Primers used were: IL-2/ 2A 5' CTCAACAAGCCCTCAATAAC 3' and IL-2/2B 5' AACCCCGTCTCTACCA $3^{\prime}$. IL-2/2A locates within the mouse IL-2 sequence whereas IL-2/2B binds to the growth hormone sequence at the $3^{\prime}$ end of the construct. The product is $410 \mathrm{bp}$ in size (20).

\section{Results}

Production of tg mice and expression of LCMV NP RNA. LCMV NP expression was directed to pancreatic $\beta$ cells of $\mathrm{H}$ $2^{\mathrm{b}} \times \mathrm{H}-2^{\mathrm{d}}$ mice using the RIP fused to cDNA encoding the NP of LCMV strain Armstrong (1). Founder mice were bred for four generations to the $\mathrm{H}-2^{\mathrm{b}}$ (C57/B16) background and made CTL responses when inoculated with LCMV that were restricted exclusively to $\mathrm{H}-2^{\mathrm{b}}\left(\mathrm{D}^{\mathrm{b}}\right)$ LCMV epitopes, i.e., GP aa $33-41$, GP aa $276-286$, NP aa $396-404$, but not to $\mathrm{H}-2^{\mathrm{d}}$ LCMV infected targets $(22-25,28)$. Such mice express the viral transgene in the islets of Langerhans and the thymus but not other tissues, i.e., brain, liver, muscle, spleen, heart, lung, or kidney (2). These RIP NP 25-3 (H-2 $\left.{ }^{\mathrm{b}}\right)$ mice were bred to RIP IL-2 $\left(\mathrm{H}-2^{\mathrm{k}} \times \mathrm{H}-2^{\mathrm{b}}\right)(\mathrm{CBA} \times \mathrm{B} 10 . \mathrm{BR})$ tg mice that expressed IL-2 in their $\beta$ cells. Such double tg mice were bred to $\mathrm{H}-2^{\mathrm{b}}(\mathrm{C} 57 \mathrm{~B} 1 / 6 \mathrm{~J})$ mice for an additional five generations. The resulting offspring made CTL responses restricted exclusively by $\mathrm{H}-2^{\mathrm{b}}$ and not by $\mathrm{H}-2^{\mathrm{k}}$ (data not shown).

RIP NP 25-3 × IL-2 doubly tg mice do not spontaneously generate anti-self (virus) CTL and do not develop IDDM. 


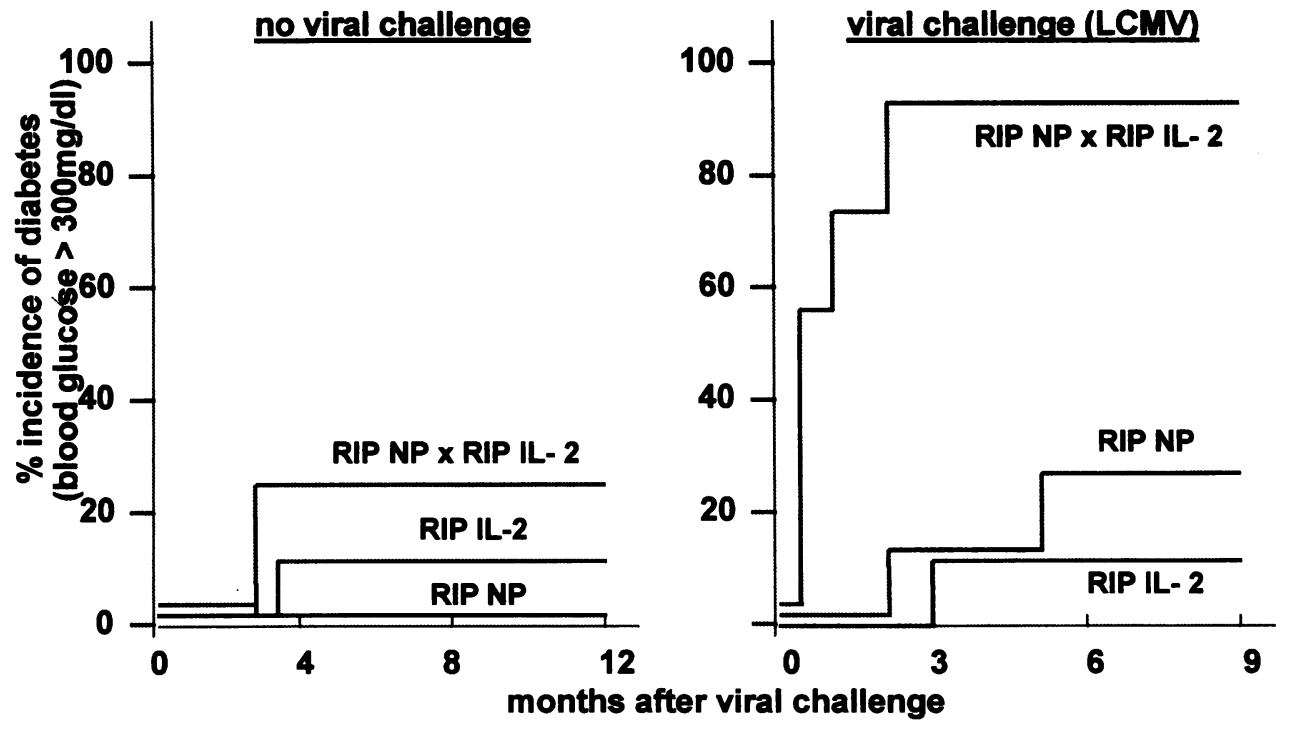

Figure 1. IL-2 expressed in the islets of Langerhans potentiates virus-induced IDDM. Incidence of IDDM (blood glucose $>300 \mathrm{mg} /$ dl) in single tg RIP IL-2 or RIP NP mice or in double tg RIP IL$2 \times$ RIP NP mice spontaneously or after infection with LCMV. Blood glucose levels were measured at 2-wk intervals as described in Methods, 10 mice/ group were analyzed. LCMVtreated mice were challenged with $2 \times 10^{5}$ pfu LCMV intraperitoneally.
IDDM as judged by blood glucose levels $>300 \mathrm{mg} / \mathrm{dl}$, insulin levels $<10 \mu \mathrm{g}$ insulin $/ \mathrm{mg}$ of pancreatic tissue, and the accumulation of mononuclear infiltrates in the islets did not occur in NP 25-3 single tg mice unless challenged with LCMV ARM (references 1 and 2, Fig. 1, and Fig. 2, panel $1 a$ ). Tg mice that locally express IL-2 in their islets spontaneously showed an accumulation of mononuclear cells in and around their islets (reference 20 and Fig. 2, panel $2 a$ ), and 10\% of such mice had elevated blood glucose levels (Fig. 1). However, mice from these transgenic lines did not spontaneously generate antiLCMV CTL (Table I). We next evaluated whether mice expressing both the viral and IL-2 genes in their islets would spontaneously generate an anti-viral (anti-self) CTL response and develop IDDM. Table I indicates that in situ expression of IL-2 does not sensitize these double tg mice to make LCMV NP-specific CTL. By contrast, focal expression of $\gamma$-IFN does (Table I). As shown by Lee et al. (29) and confirmed here, splenic lymphocytes from double tg mice that expressed both LCMV NP (line NP 25-3) and $\gamma$-IFN (RIP $\gamma$-IFN) generate LCMV NP-specific CTL. Lymphocytes harvested from NP 25$3-\mathrm{H}-2^{\mathrm{b}}$ or $\mathrm{H}-2^{\mathrm{d}}$ tg mice fail to spontaneously generate NP CTL and have an incidence of IDDM $<5 \%(1,2)$. Thus, of 210 RIP NP mice studied, only 2 had blood glucose values of $>300$ $\mathrm{mg} / \mathrm{dl}$ after observation for $15 \mathrm{mo}$, and none of those tested spontaneously made anti-viral CTL $(1,2)$. Both hyperglycemic mice failed to display mononuclear cell infiltrates in the islets, but instead showed swollen, "ground-glass" appearing islet cells (1). RIP IL-2 single tg mice had an incidence of diabetes of $10 \%$, with 3 of 30 observed mice displaying blood glucose $>300 \mathrm{mg} / \mathrm{dl}$ (Fig. 1). Double tg (RIP LCMV NP $\times$ RIP IL2) mice spontaneously develop IDDM with an incidence of $25 \%$ over a 12 -mo observation period, with 3 out of 12 mice having blood glucose values above $300 \mathrm{mg} / \mathrm{dl}$.

Immunohistochemical analysis of islets from RIP LCMV NP 25-3 $\times$ RIP IL-2 double tg mice. The islets of doubly tg mice (RIP NP $\times$ RIP IL-2) or single tg mice expressing IL-2 only (RIP IL-2) showed infiltration primarily of $\mathrm{CD} 4^{+}$cells (Fig. 2 , panel $2 b$ ) and B lymphocytes (Fig. 2, panel $2 e$ ) with relatively less $\mathrm{CD}^{+}$cells (Fig. 2, panel $2 d$ ). Macrophages were noted only in the periphery of islets (Fig. 2, panel $2 c$ ). Expression of MHC class I (data not shown) and MHC class II on islet cells was present only in RIP IL-2 tg mice or double tg RIP NP $\times$ RIP IL-2 mice (Fig. 2, panel $2 f$ compared with panel 1f ). By contrast, neither infiltration of $\mathrm{CD}^{+}$or $\mathrm{CD} 8^{+}$cells, macrophages, B lymphocytes (Fig. 2, panels $1 b-1 e$ ) nor expression of MHC glycoproteins on islet cells (Fig. 2, panel $1 f$ ) was noted in islets of RIP NP tg mice. FACS ${ }^{\bullet}$ analysis showed elevated levels of $\mathrm{CD}^{+}$lymphocytes in RIP tg mice with IL2 expression ( 50 vs $15 \%$ in non-IL- 2 mice, Table II). LCMVspecific IgG antibody levels measured by ELISA 3 wk after viral infection were $1: 10,000$ in RIP IL-2 mice and $1: 6,000$ in RIP NP mice (eight mice per group) (2).

RIP NP 25-3 single tg and the double tg RIP NP 25-3 $\times I L$ 2 mice fail to mount a primary CTL response to the viral NP after LCMV challenge. Both non-tg (normal controls) and RIP IL-2 mice mount a vigorous CTL response to LCMV NP and GP after challenge with LCMV (Table II). By contrast, single or double tg RIP LCMV NP mice fail to generate a primary CTL response to LCMV NP but generate a CTL response to LCMV GP that is equivalent to the observed GP CTL response in non-tg controls (Table II).

RIP NP 25-3 × IL-2 doubly tg mice display a markedly accelerated course of IDDM after LCMV challenge. Fig. 1 shows that at $8 \mathrm{mo}$ after receiving $1 \times 10^{5}$ pfu of LCMV intraperitoneally, both NP 25-3 and IL-2 single tg mice develop relatively low incidences of IDDM $(<10 \%$ for RIP IL- 2 and $30 \%$ for RIP NP 25-3, 16-20 mice/group). By contrast, viral inoculated double tg mice (10 mice/group) have an incidence of IDDM of $70 \%$ at $1 \mathrm{mo}$ and $>90 \%$ at $2 \mathrm{mo}$ after viral challenge. Immunochemical analysis of the infiltrating cells showed a pattern similar to that of IL-2 single tg mice before viral challenge (Fig. 2, panels $2 a-2 f$ compared with Fig. 3 ), except that the number of $\mathrm{CD} 8{ }^{+}$lymphocytes found in the islet infiltrate of doubly tg mice was markedly increased (Fig. $3 e$ compared with Fig. 2, panel $2 d$ ). Expression of the viral tg in single and double tg mice was assessed by immunohistochemistry. For islets studied from four mice of each group, the expression of LCMV NP in $\beta$ cells was equivalent in RIP LCMV NP as compared with RIP LCMV NP $\times$ RIP IL-2 mice. 

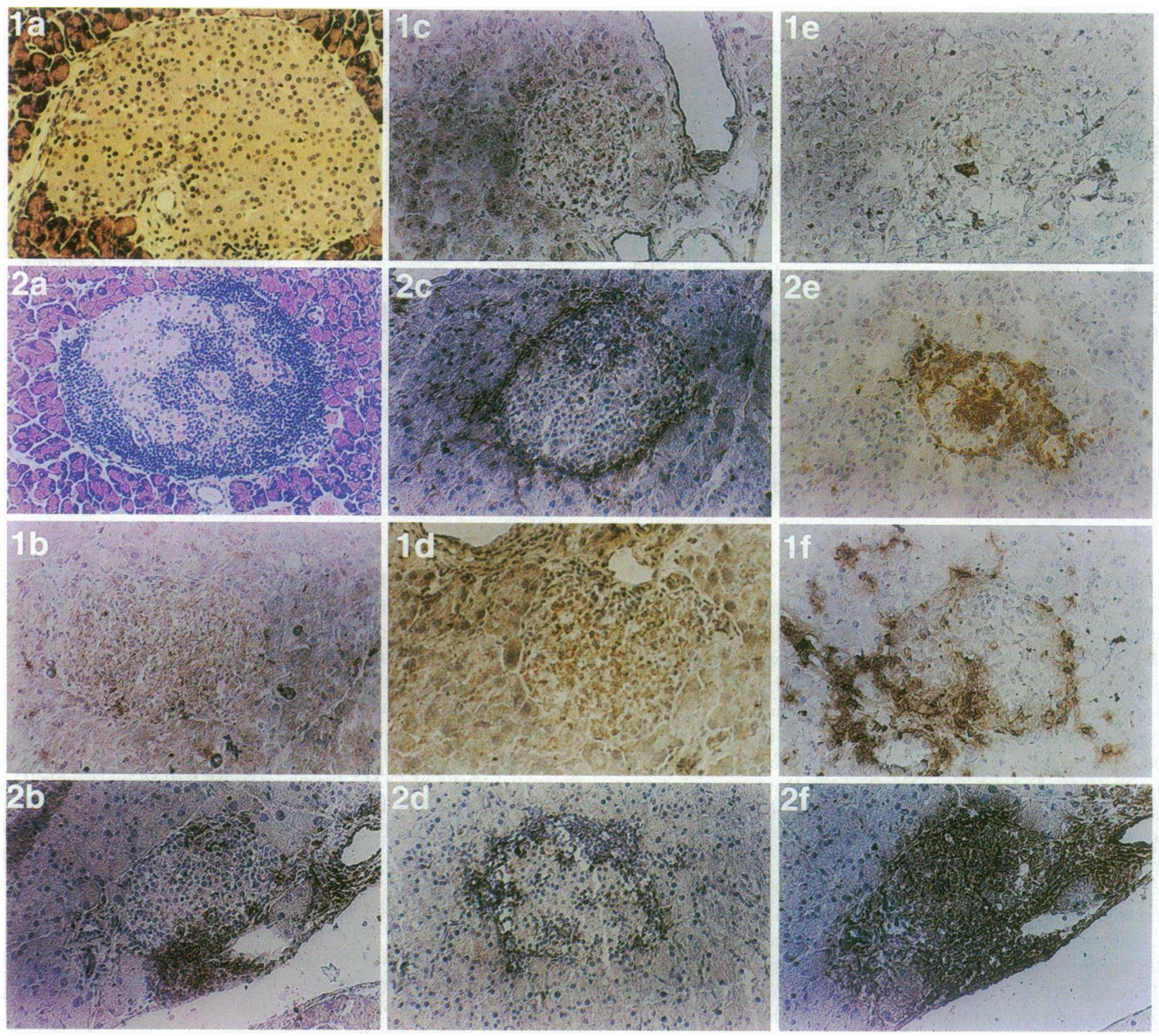

Figure 2. Histopathology and immunochemical analysis of islets of Langerhans in non-viral treated RIP IL-2 or RIP IL-2 $\times$ NP $25-3$ compared with RIP NP tg mice. Immunohistochemical staining of consecutive 5-6- $\mathrm{m}$ sections of islets was carried out as described in Methods. At least three different areas were surveyed per mouse. 10 mice were studied from each experimental group, representative sections are shown that were similar for each mouse in that particular group. Sections shown were processed and stained at the same time. Findings in RIP IL-2 single tg and RIP NP 25-3 $\times$ RIP IL-2 double tg mice were identical. Magnification is 200-fold. Panels indicate tg mouse and the particular strain under observation. $1 a$, RIP NP, HE; $2 a$, RIP IL-2, HE; $1 b$, RIP NP, CD4; $2 b$, RIP IL-2, CD4; $1 c$, RIP NP, F4/80; $2 c$, RIP IL-2, F4/80; $1 d$, RIP NP, CD8; $2 d$, RIP IL-2, CD8; $1 e$, RIP NP, B220; $2 e$, RIP IL-2, B220; $1 f$, RIP NP, class II; and $2 f$, RIP IL-2, class II.

Breaking of unresponsiveness in RIP IL-2 $\times$ RIP NP 25-3 doubly tg mice is associated with the generation of CD4 help for anti-self (virus) $C D 8^{+} \mathrm{CTL}$. We showed previously that NP-specific $\mathrm{CD}^{+}{ }^{+}$lymphocytes infiltrate the islets of Langerhans and that adoptive transfer of this purified cell population caused IDDM in a virus-specific MHC-restricted manner (1, 2). Breaking of initial unresponsiveness to LCMV NP in RIP NP tg mice occurred over time and was $\mathrm{CD}^{+}{ }^{+}$help dependent (2). LCMV NP-specific CTL could only be recovered from mice when they developed IDDM (2). The sequence of LCMV NP recognized by LCMV-specific CTL restricted by $\mathrm{H}-2^{\mathrm{b}}$ is FQPQNGQFI, aa 396-404 (22-25, 30). Observations made with CTL from RIP NP $\times$ RIP IL-2 double tg mice and presented in Table III parallel these previous findings. While primary CTL to LCMV NP were not generated by RIP NP $\times$ IL2 double tg mice after LCMV immunization (Table II), they nevertheless could be obtained in association with the onset of IDDM from both spleens and pancreatic target tissue. These $\mathrm{CD} 8{ }^{+}$anti-NP ( "anti-self ") CTL depended on CD4 ${ }^{+}$help, as depletion of $\mathrm{CD} 4{ }^{+}$cells prevented their generation and the onset of IDDM (Table III). The anti-viral $\mathrm{H}-2^{\mathrm{b}} \mathrm{CTL}$ recovered from RIP NP 25-3 $\times$ RIP IL-2 double tg mice recognized the same NP amino acid sequence FQPQNGQFI as did CTL from nontg ${\mathrm{H}-2^{\mathrm{b}}}^{\mathrm{b}}$ controls or RIP IL-2 mice (data not shown). Affinity 
Table I. Doubly tg RIP NP 25-3 × RIP IL-2 Mice Do Not Spontaneously Generate LCMV-specific CTL

\begin{tabular}{|c|c|c|c|c|c|c|}
\hline \multirow[b]{3}{*}{ Secondary CTL } & \multicolumn{6}{|c|}{ Percent $\mathrm{Cr}^{51}$ release from target cells } \\
\hline & \multicolumn{3}{|c|}{$\mathrm{H}-2^{\mathrm{b}}$} & \multicolumn{3}{|c|}{$\mathrm{H}-2^{\mathrm{d}}$} \\
\hline & ARM & vvGP & vvNP & ARM & vvGP & vvNP \\
\hline $\mathrm{H}-2^{\mathrm{b}}+\mathrm{LCMV}$ & $36 \pm 4$ & $25 \pm 3$ & $24 \pm 4$ & Nil & Nil & $3 \pm 2$ \\
\hline $\mathrm{H}-2^{\mathrm{d}}+\mathrm{LCMV}$ & $5 \pm 1$ & Nil & Nil & $50 \pm 7$ & Nil & $35 \pm 4$ \\
\hline RIP-NP 25-3 no LCMV alone & 0 & 0 & 0 & 0 & 0 & 0 \\
\hline$\times$ RIP IL-2 $\left(\mathrm{H}-2^{\mathrm{b}}\right)$ & 0 & 0 & 0 & $2 \pm 1$ & $1 \pm 0$ & $3 \pm 1$ \\
\hline$\times$ RIP IFN- $\gamma\left(\mathrm{H}-2^{\mathrm{d}}\right)^{*}$ & 0 & 0 & 0 & $35 \pm 8$ & 0 & $20 \pm 5$ \\
\hline RIP IL-2 no LCMV & 0 & 0 & 0 & 0 & 0 & 0 \\
\hline RIP IFN- $\gamma$ no LCMV & 0 & 0 & 0 & 0 & 0 & 0 \\
\hline
\end{tabular}

CTL activity measured in non-viral treated RIP NP 25-3 mice, RIP IL-2 mice, and doubly tg mice (RIP NP $\times$ IL-2 or RIP NP $\times$ IFN- $\gamma$ ). Groups displayed contained at least five mice and the mean value \pm 1 standard devation is shown. Splenocytes were harvested from 4-mo-old non-viral treated double tg mice and from virus-infected single tg mice (RIP NP or RIP IL-2) or non tg controls (Balb/cByJ or C57B1/6) 45-90 d after infection with $2 \times 10^{5}$ pfu LCMV intraperitoneally. The splenocyte suspension was cultivated for $8 \mathrm{wk}$ in vitro on feeder macrophages (see Methods). Thereafter, CTL activity was determined by a $5-\mathrm{h}^{51} \mathrm{Cr}$ release assay. Target cells were Balb (H-2 $\left.{ }^{\mathrm{d}}\right)$ and $\mathrm{MC} 57$ (H-2 $)$ fibroblasts infected with LCMV ARM or vaccinia viruses expressing NP or GP of LCMV. The effector to target ratio used was 20:1, 10:1, and 5:1 with data for 10:1 shown. Samples were run in triplicate, variance was $<10 \%$, and numbers shown reflect the mean value. * See reference 29 .

studies using log dilutions of peptide (FQPQNGQFI) from $10^{-6}$ to $10^{-15} \mathrm{M}$ to coat target cells revealed no affinity differences between CTL generated in RIP NP or RIP IL-2 tg mice or nontg littermates.

\section{Discussion}

Using a model of virus-induced autoimmune diabetes, we report here two novel findings. First, the cytokine IL-2 cannot, by itself, break immunologic ignorance in vivo. Despite the focal expression of IL-2 in the islets, activation of unresponsive potentially anti-self (viral) $\mathrm{T}$ lymphocytes does not occur. Such anti-self (viral) CTL are only activated after subsequent viral infection indicating that other factors in addition to IL-2 are required. Of interest, failure to break ignorance occurs despite the fact that the focal production of IL- 2 in the islets induces an inflammatory response in and around the pancreatic $\beta$ cells. The second finding is that IL-2 markedly reduces the time required for the onset of IDDM and enhances the incidence of IDDM once the anti-self CTL response has been initiated by a viral infection.

The etiology of autoimmune type I diabetes in humans is not clear $(31,32)$. Among possible pathogenetic triggers, environmental agents such as viruses have been implicated. One hypothesis postulates two events for induction of autoimmune IDDM. First, contact with a virus early in life results in persistence of viral antigen in the islets of Langerhans. The second event is an infection with the same virus or antigenetically related pathogen later in life. A consequence of the infection is the induction of an immune response that crossreacts with viral (self) antigens in the pancreas and leads to destruction of the islet cells and results in IDDM. This hypothesis is supported

Table II. RIP IL-2 × RIP NP Mice Fail To Generate a Primary LCMV CTL Response to the Viral NP

\begin{tabular}{|c|c|c|c|c|c|c|c|}
\hline & \multicolumn{2}{|c|}{$\mathrm{H}-2^{\mathrm{b}}$ splenocytes } & \multicolumn{5}{|c|}{ Specific $\mathrm{Cr}^{51}$ release $(\%)$} \\
\hline & \multirow{2}{*}{$\begin{array}{c}\% \\
\text { CD4 }\end{array}$} & \multirow{2}{*}{$\begin{array}{c}\% \\
\text { CD8 }\end{array}$} & \multicolumn{4}{|c|}{$\mathrm{H}-2^{\mathrm{b}}$} & \multirow{2}{*}{$\frac{\mathrm{H}-2^{\mathrm{d}}}{\mathrm{ARM}}$} \\
\hline & & & ARM & vvNP & vvGP & vvGP1 & \\
\hline RIP NP & $15 \pm 3$ & $23 \pm 4$ & $450 \pm 5$ & 0 & $22 \pm 4$ & $27 \pm 3$ & 0 \\
\hline RIP IL-2 & $45 \pm 5$ & $28 \pm 4$ & $55 \pm 19$ & $30 \pm 7$ & $28 \pm 5$ & $40 \pm 8$ & $3 \pm 1$ \\
\hline RIP IL- $2 \times$ RIP NP & $50 \pm 9$ & $20 \pm 8$ & $28 \pm 8$ & 0 & $15 \pm 7$ & $40 \pm 6$ & $2 \pm 1$ \\
\hline Non-tg & $18 \pm 4$ & $28 \pm 7$ & $32 \pm 6$ & $25 \pm 5$ & $27 \pm 4$ & $33 \pm 7$ & $7 \pm 4$ \\
\hline
\end{tabular}

CTL activity in RIP IL-2 or RIP NP mice on day 7 after challenge with $2 \times 10^{5}$ pfu LCMV intraperitoneally. Data are recorded as the mean value $\pm 1 \mathrm{SD}$, at least six mice per group. CTL activity was assayed at $7 \mathrm{~d}$ after administration of $2 \times 10^{5}$ pfu of LCMV ARM 53b intraperitoneally. tg mice selected for analysis of CTL were those having normal blood glucose $(180 \pm 20 \mathrm{mg} / \mathrm{dl})$. Single cell suspension of spleen lymphocyte effectors was used at effector to target ratios of 50:1 and 25:1 with data for 50:1 shown. Target cells were H-2 ${ }^{\mathrm{b}}$ (MC57) and H-2 ${ }^{\mathrm{d}}$ (BALB/C17) fibroblasts labeled with ${ }^{51} \mathrm{Cr}$ and used either uninfected or infected for $48 \mathrm{~h}$ with LCMV ARM or vaccinia virus expressing LCMV GP or expressing LCMV NP (1). Samples were run in triplicate and mean determination was obtained in a 5-h ${ }^{51} \mathrm{Cr}$ release assay. Variance was $<10 \%$. CD4 and CD8 levels in PBL from individual mice were determined by FACS ${ }^{\circledR}$ (see Methods). Values shown here are representative for CD4 and CD8 cell counts found in 15 other unprimed RIP IL-2 mice. 

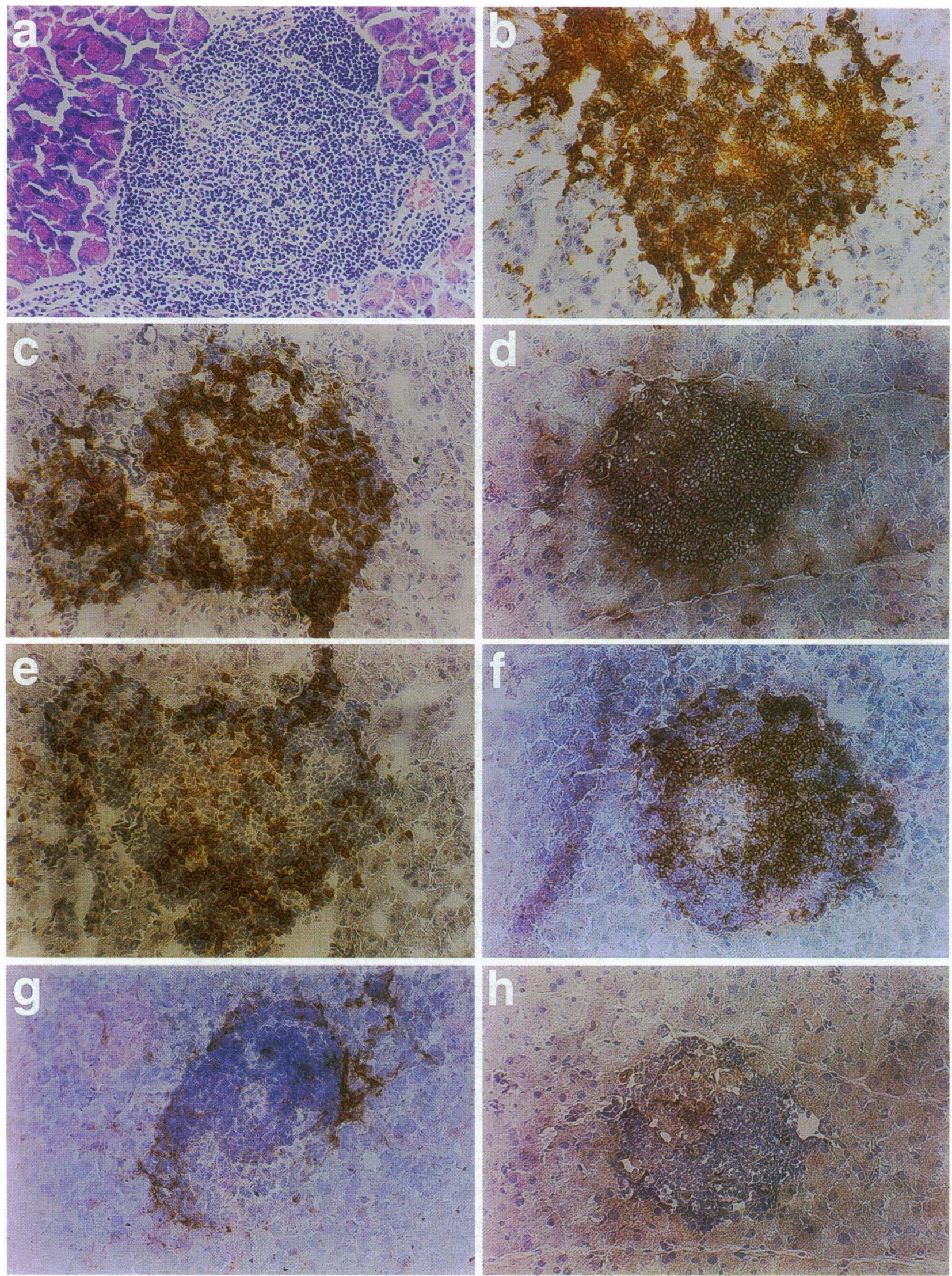
Table III. Secondary CTL Reactivity in RIP IL-2 $\times$ RIP NP Mice $60 \mathrm{~d}$ after Infection with LCMV ARM

\begin{tabular}{|c|c|c|c|c|c|c|c|c|c|c|c|c|}
\hline \multicolumn{4}{|c|}{ Transgenic $\left(\mathrm{H}-2^{\mathrm{b}}\right)$ mice } & \multirow[b]{3}{*}{ Mice } & \multirow{3}{*}{$\begin{array}{c}\text { Ratio } \\
\text { E:T }\end{array}$} & \multicolumn{6}{|c|}{ Specific ${ }^{51} \mathrm{Cr}$ release $(\%)$} & \multirow[b]{3}{*}{ Diabetes } \\
\hline \multirow[b]{2}{*}{ RIP IL-2 } & \multirow{2}{*}{$\begin{array}{l}\text { RIP } \\
\text { NP }\end{array}$} & \multicolumn{2}{|c|}{ FACS $\odot$} & & & \multicolumn{5}{|c|}{$\mathrm{H}-2^{\mathrm{b}}$} & \multirow{2}{*}{$\frac{\mathrm{H}-2^{\mathrm{d}}}{\mathrm{ARM}}$} & \\
\hline & & $\% \mathrm{CD} 4$ & $\% \mathrm{CD} 8$ & & & ARM & vvNP & vvGP & vvGP1 & vvGP2 & & \\
\hline No & No & 18 & 24 & 68 & $5: 1$ & 80 & 64 & 35 & 63 & 30 & 7 & No \\
\hline+ & No & 52 & 22 & 23 & $5: 1$ & 76 & 27 & 31 & 16 & 41 & 3 & No \\
\hline+ & No & 44 & 18 & 18 & $5: 1$ & 55 & 31 & 15 & 33 & 15 & 5 & No \\
\hline No & + & 19 & 28 & 32 & $5: 1$ & 34 & Nil & 26 & ND & ND & Nil & No \\
\hline \multicolumn{13}{|c|}{ CD4-depleted } \\
\hline+ & + & $2 \pm 1$ & $27 \pm 4$ & 5 mice & $5: 1$ & $73 \pm 15$ & Nil & $33 \pm 8$ & $38 \pm 7$ & $42 \pm 10$ & Nil & No \\
\hline \multicolumn{13}{|c|}{ CD8-depleted } \\
\hline+ & + & $55 \pm 8$ & $3 \pm 2$ & 5 mice & $5: 1$ & $9 \pm 3$ & $8 \pm 2$ & $1 \pm 1$ & $5 \pm 2$ & Nil & $1 \pm 1$ & No \\
\hline \multicolumn{13}{|l|}{ Not depleted } \\
\hline+ & + & $51 \pm 13$ & $20 \pm 11$ & 4 mice & $5: 1$ & $38 \pm 12$ & $28 \pm 9$ & $24 \pm 8$ & $22 \pm 9$ & $19 \pm 5$ & Nil & Yes \\
\hline
\end{tabular}

CTL activity of secondary cultures derived from RIP IL- $2 \times$ RIP NP mice before and after onset of IDDM after challenge with $2 \times 10^{5}$ pfu LCMV intraperitoneally. Data from individual mice $(68,23,18$, and 32$)$ or the mean \pm 1 SD from five CD4-depleted or five CD8-depleted or four RIP IL$2 \times$ RIP NP mice are shown. CTL activity was assayed from secondary cultures of spleens harvested $60 \mathrm{~d}$ (no IDDM or IDDM) after administration of $1 \times 10^{5} \mathrm{pfu}$ of LCMV ARM 53b intraperitoneally. tg mice selected for analysis of secondary CTL were those having normal blood glucose $(180 \pm 20 \mathrm{mg} / \mathrm{dl})$ at day $30-45$ or elevated blood glucose $(>350 \mathrm{mg} \%)$ at day 120 after LCMV challenge. Secondary CTLs were used as effector to target ratios of 5:1 or 2.5:1 with data for 5:1 shown. Target cells were $\mathrm{H}-2^{\mathrm{b}}$ (MC57) and H-2 ${ }^{\mathrm{d}}$ (BALB/C17) fibroblasts labeled with ${ }^{51} \mathrm{Cr}$ and used either uninfected or infected $48 \mathrm{~h}$ with LCMV ARM or vaccinia virus expressing LCMV GP or LCMV NP (1). Samples were run in triplicate and mean determination was obtained in a $5-6 \mathrm{~h}^{51} \mathrm{C}$ release assay. Variance was $<10 \%$. Splenic lymphocytes were obtained from mice immunochemically depleted of $\mathrm{CD}^{+}$or $\mathrm{CD}^{+}$cells before viral challenge where indicated. Depletion of CD4 and CD8 expressing lymphocytes was done as described in Methods. Mice that did not become diabetic were followed up to 10 mo.

by development of the RIP LCMV tg mouse model and its subsequent manipulation with viral infection $(1,2,33)$.

Development of IDDM was dependent on the generation of LCMV specific (anti-self) CD8 ${ }^{+}$CTL in all tg lines studied. However, several lines showed a rapid onset of IDDM, with diabetes occurring within $10-14 \mathrm{~d}(2,33)$ while other lines displayed a slow onset, with diabetes occurring 2-5 mo after viral challenge $(1,2)$. Those with the rapid onset IDDM expressed the tg only in the pancreas, did not require $\mathrm{CD} 4^{+}$help, and generated high-avidity CD8 ${ }^{+}$CTL (2). The slow onset IDDM was studied in this report and is characterized by expression of the th in the thymus as well as the pancreas, generation of lower activities of anti-self $\mathrm{CD} 8^{+} \mathrm{CTL}$, and the need of $\mathrm{CD}^{+}{ }^{+}$help for the generation of these CTL (2). It is during the delay phase after viral infection until the onset of IDDM that ignorance (unresponsiveness) to the viral tg (self-antigen) in the pancreas is broken and autoreactive $T$ cells are activated. Based on in vitro and in vivo studies, several cytokines, especially IL-2, have been implicated in this activation process and thus with the pathogenesis of IDDM (33-35).

To test the ability of IL-2 to either break immunologic ignorance of $\mathrm{CD} 8{ }^{+} \mathrm{CTL}$ in vivo or to enhance autoimmune disease once initiated, we used tg technology to focally express IL-2 and the (self) viral transgene in the islets of Langerhans. tg mice that express constitutive levels of $\mathrm{IL}-2$ alone in their pancreas (RIP IL-2 transgenics) have been characterized (20). When IL-2 is expressed at a high level, mice die at an early age due to destruction of the pancreas associated with a predominantly macrophage-containing inflammatory infiltrate. Those lines expressing IL-2 at a moderate to low level develop periand intra-islet infiltrates over time. The infiltrates are comprised mainly of $\mathrm{CD} 4^{+}$cells. However, spontaneous incidence of diabetes is infrequent and autoimmunity is not detected (20). We mated tg mice that expressed low levels of IL-2 to RIP NP 253 mice that expressed LCMV NP in the pancreas but do not spontaneously develop IDDM. The double tg progeny (RIP LCMV $\times$ RIP IL-2) were then analyzed to see whether IL-2 could break immunologic ignorance. The focal presence of IL2 did not lead to activation of anti-self (viral tg) CTL or to a dramatically higher incidence of IDDM in these double tg mice (incidence of IDDM $=10 \%$ in $\mathrm{IL}-2 \mathrm{tg}$ mice, $25 \%$ in double $\mathrm{tg}$ mice) indicating that IL-2 alone was insufficient. The inability to break immunologic ignorance occurred despite IL-2-induced infiltration of islets with CD4 cells and B cells coupled with elevated expression of MHC class I and II molecules on islet cells. Although $\mathrm{IL}-2$ is able to activate cytotoxic $\mathrm{T}$ cells under

Figure 3. Histopathology and immunochemical analysis of islets of Langerhans in RIP IL-2 $\times$ NP 25-3 transgenic mice 8 wk after infection with $2 \times 10^{5}$ pfu LCMV intraperitoneally. Immunohistochemical staining of consecutive 5-6- $\mu \mathrm{m}$ sections of islets was carried out as described in Methods. At least three different areas were surveyed per mouse. 10 mice were studied from each experimental group, representative sections are shown that were similar for each mouse in that particular group. Sections shown were processed and stained at the same time. Magnification is 200-fold. Panels indicate the particular stain under observation. $a$, hematoxylin/eosin; $b, \mathrm{MHC}$ class II; $c, \mathrm{CD}^{+} ; d, \mathrm{MHC}$ class I; $e, \mathrm{CD}^{+} ; f$, $\mathrm{B} 220 ; g, \mathrm{~F} 4 / 80$; and $h$, vascular cell adhesion molecule. 
specific conditions in vitro $(5,10)$, we could find no evidence that it performed that task in vivo (Tables I and II, Figs. 2 and 3 ) without virus priming. Thus, while IL-2 supports the growth of T lymphocytes, both Th1 and Th2, other cytokines like IFN$\gamma$ are probably needed to skew the response to Th1-cells (36, 37 ). This concept is supported by the ability of $\gamma$-IFN to spontaneously generate anti-viral CTL in the RIP LCMV tg mice (Table I). $\beta$ cells do not function as proper antigen-presenting cells (APCs) even in the presence of IL-2, possibly because of the lack of costimulation signal(s). Recent studies (references 38 and 39 and von Herrath, M. G., S. Guerder, R. Flavell, and M. B. A. Oldstone, manuscript in preparation $)(38,39)$ indicate that expression of B7.1 on target or islet cells makes them competent APCs for the induction of CTL killing. The twofold higher incidence of spontaneous IDDM observed in double tg mice (RIP IL- $2 \times$ RIP NP) compared with single tg littermates expressing IL-2 alone is not due to specific activation of antiself (virus) CTL (Table I). Perhaps accumulation of transgene products renders $\beta$ cells more susceptible for destruction. Alternatively, the activation of precursor CTL (pCTL) might occasionally occur but in numbers too low to be measured in the CTL assay or too few to produce IDDM. Heath and his colleagues (14) have found in their RIP-K ${ }^{b}$ tg model that autoimmune diabetes only occurs in triple tg mice expressing IL-2, $\mathrm{K}^{\mathrm{b}}$, and the $\mathrm{T}$ cell receptor specific for $\mathrm{K}^{\mathrm{b}}$ on $>90 \%$ of their $T$ cells indicating that the number of self-antigen-specific PCTL is important with lower numbers not being sufficient to cause disease.

While IL-2 does not lead to the breaking of immunologic ignorance and autoimmunity, it does, however, potentiate the development of autoimmunity in double tg mice after viral infection (95\% incidence of IDDM in double tg mice versus $30 \%$ incidence in RIP NP single tg mice). A possible scenario is that viral (self) antigen has to be presented to T cells by "professional" APCs to lead to their specific activation. Presentation of viral NP on the $\beta$ cells without costimulation cannot activate $T$ cells and therefore does not lead to spontaneous autoimmunity even in the presence of IL-2. However the viral infection provides the immune system with a "proper" presentation of viral antigen. Once initiated, this process can be potentiated by the action of $\mathrm{IL}-2$, and the activated $\mathrm{T}$ cells are then able to react with viral antigen presented on $\beta$ cells. Another possibility is that viral infection unleashes a battery of cytokines that favors the switch to a Th1 phenotype and the development of IDDM. Generation of IDDM in RIP NP $\times$ RIP IL-2 mice is still CD4 ${ }^{+}$ help dependent (Table III), indicating that focal expression of $\mathrm{IL}-2$ alone cannot substitute $\mathrm{CD} 4{ }^{+}$help. Hence, other CD4 ${ }^{+}$ helper cell-dependent factors such as $\gamma$-IFN (40) are likely needed for development of IDDM.

Recent studies with IL-2 knockout mice show that IL-2 has no effect on the generation of a primary LCMV-specific CTL response (41). In our model, however, primary anti-LCMV NP CTL are not found because most are deleted due to thymic expression of NP (Table II and [2, 42]). Thus, IL-2 has an effect by facilitating the breaking of ignorance and the generation of secondary NP-specific CTL. These findings suggest a differential role for IL-2 in events required for the primary antiviral immune response and rapid onset IDDM as compared with its role in the slower onset IDDM. Observations supporting this concept come from work of Biron and colleagues $(43,44)$ in demonstrating that $\mathrm{CD}^{+}$cells and $\mathrm{IL}-2$ are required for sustaining the anti-LCMV immune response over time.

The incidence of IDDM for LCMV-challenged RIP NP 253 mice generated by breeding to the RIP IL-2 mice $\left(\mathrm{H}-2^{\mathrm{b}}\right.$ [C57B1/6 × B10.BR/CBA] background) was lower (Fig. 3) than described previously for RIP NP 25-3 mice bred to the $H$ $2^{\mathrm{b}}$ (C57B1/6) background (2). This suggests that non-MHC linked B10.BR/CBA genes likely play a role in suppressing the ordinarily expected kinetics for IDDM in C57B1/6 $\left(\mathrm{H}-2^{\mathrm{b}}\right)$ mice. Thus, the introduction of genes from the CBA or B10.BR backgrounds altered the susceptibility and kinetics of IDDM, even though the double tg mice used were backcrossed to $\mathrm{H}$ $2^{\mathrm{b}}(\mathrm{C} 57 \mathrm{~B} 1 / 6 \mathrm{~J})$ for five generations and made CTL responses restricted by $\mathrm{H}-2^{b}$ and not $\mathrm{H}-2^{\mathrm{k}}$ (CBA). Other studies (45) have shown that the overall genotype still differs up to $46 \%$ at the fifth backcross depending on the gene locus linkage.

The use of the double tg model can allow the dissection of the specific role ( $\mathrm{s}$ ) played by cytokines in vivo in the pathogenesis of several diseases including IDDM. As experience grows with tg models on different genetic backgrounds manipulated by viral or environmental triggers, the multifactorial etiology for the pathogenesis of IDDM and prevention strategies for IDDM should become clearer.

\section{Acknowledgments}

The authors thank Dr. Iain Campbell and Dr. Nora Sarvetnick for helpful discussions, Nora Sarvetnick and Myung S. Lee for assistance and usage of the RIP $\gamma$-interferon transgenic mice, and Gay Schilling and Amy Goddard for assistance with the manuscript.

This work was supported by U. S. Public Health Service grant AG04342. Matthias G. von Herrath is currently supported by a fellowship of the Juvenile Diabetes Foundation International and previously by a fellowship of the Deutsche Forschungsgemeinschaft.

\section{References}

1. Oldstone, M. B. A., M. Nerenberg, P. Southern, J. Price, and H. Lewicki. 1991. Virus infection triggers insulin-dependent diabetes mellitus in a transgenic model: role of the anti-self (virus) immune response. Cell. 65:319-331.

2. von Herrath, M. G., J. Dockter, H. Lewicki, and M. B. A. Oldstone. 1994. How virus induces a rapid and slow onset IDDM in a transgenic model. Immunity. 1:231-242.

3. Chiodetti, L., and R. Schwartz. 1992. Induction of competence to respond to IL-4 by CD4+ helper type 1 cells requires costimulation. J. Immunol. 149:901 910.

4. Gillis, S., M. Ferm, W. Ou, and K. A. Smith. 1978. T-cell growth factor, parameters for production and a quantitative microassay for activity. J. Immunol. 120:2027-2032.

5. Bass, H. Z., N. Yamashita, and L. T. Clement. 1992. Heterogenous mechanisms of human CTL generation. I. Differential helper cell requirement for the generation of CTL from CD8+ precursor subpopulations. J. Immunol. 149:24892495.

6. Paul, W. E., and R. A. Seder. 1994. Lymphocyte responses and cytokines. Cell. 76:241-251.

7. Beverly, B., S. MoKang, M. Lenardo, and R. Schwartz. 1992. Reversal of in vitro T-cell clonal anergy by IL-2 stimulation. Int. Immunol. 4:661-671.

8. Grimm, E. A., and L. Owen-Schaub. 1991. The IL-2 mediated amplification of cellular cytotoxicity. J. Cell. Biochem. 45:335-339.

9. Ley, V., P. Langade-Demoyen, P. Kourilsky, and E. Larsson-Sciard. 1991. IL-2 dependent activation of tumor specific cytotoxic T-lymphocytes in vivo. Eur. J. Immunol. 21:851-854.

10. Brisette-Storkus, C. S., D. Kostyu, C. Boyer, and J. Dawson. 1990. Induction of HLA specific CTL to nonimmunogenic, heat-inactivated lymphocytes by IL-2. Transplantation (Baltimore). 50:862-869.

11. Bertagnolli, M., Y. Takai, and S. H. Hermann. 1991. IL-4 supported induction of cytolytic T-lymphocytes requires IL-2 and IL-6. Cell. Immunol. 133:327-341. 
12. Moscovitch-Lopatin, M., R. Petrillo, O. Pankewycz, E. Hadro, C. Bleackley, T. Strom, and K. J. Wieder. 1991. IL-2 counteracts the inhibition of CTL by cholera toxin in vitro and in vivo. Eur. J. Immunol. 21:1439-1444.

13. Fast, L. D. 1992. Generation and characterization of IL-2 activated veto cells. J. Immunol. 149:1510-1515.

14. Heath, W. R., J. Allison, M. W. Hoffmann, G. Schonrich, G. Hammerling, B. Arnold, and J. F. A. P. Miller. 1992. Autoimmune diabetes as a consequence of locally produced interleukin-2. Nature (Lond.). 359:547-549.

15. Jones, L. A., L. T. Chin, G. R. Meriam, L. M. Nelson, and A. M. Kruisbeck. 1990. Failure of clonal deletion in neonatally thymectomized mice: tolerance is preserved through clonal anergy. J. Exp. Med. 172:1277-1283.

16. Andreu-Sanchez, J., I. M. Dealboran, M. A. R. Marcos, A. Sanchez Movilla, A. C. Martinez, and G. Kroemer. 1991. Interleukin-2 abrogates the nonresponsive state of T-cells expressing a forbidden TcR repertoire and induces autoimmune disease in neonatally thymectomized mice. J. Exp. Med. 173:1323-1329.

17. Schols, D., B. Vandekerckhove, D. Jones, and M. G. Roncarolo. 1994. IL-2 reverses human T-cell unresponsiveness induced by thymic epithelium in SCID-hu mice. J. Immunol. 152:2198-2206.

18. Hanahan, D. 1985. Heritable formation of pancreatic $\beta$-cell tumors on transgenic mice expressing recombinant insulin/simian virus 40 oncogenes. $\mathrm{Na}$ ture (Lond.). 315:115-122.

19. Southern, P. J., M. K. Singh, Y. Riviere, D. R. Jacoby, M. J. Buchmeier, and M. B. A. Oldstone. 1987. Molecular characterization of the genome S RNA segment from lymphocytic choriomeningitis virus. Virology. 157:145-155.

20. Allison, J., L. Malcolm, N. Chosich, and J. F. A. P. Miller. 1992. Inflammation but not autoimmunity occurs in transgenic mice expressing constitutive levels of interleukin-2 in islet beta-cells. Eur. J. Immunol. 22:1115-1121.

21. Dutko, F. J., and M. B. A. Oldstone. 1983. Genomic and biological variation among commonly used lymphocytic choriomeningitis virus strains. $J$. Gen. Virol. 64:1689-1698.

22. Whitton, J. L., P. J. Southern, and M. B. A. Oldstone. 1988. Analysis of the CTL responses to glycoprotein and nucleoprotein components of LCMV. Virology. 162:3211-3217.

23. Whitton, J. L., J. R. Gebhard, H. Lewicki, A. Tishon, and M. B. A. Oldstone. 1988. Molecular definition of a major cytotoxic T lymphocyte epitope in the glycoprotein of lymphocytic choriomeningitis virus. J. Virol. 62:687-695.

24. Klavinskis, L. S., J. L. Whitton, and M. B. A. Oldstone. 1989. Molecularly engineered vaccine which expresses and immunodominant $\mathrm{T}$-cell epitope induces cytotoxic $\mathrm{T}$ lymphocytes that confer protection from lethal virus infection. $J$. Virol. 6:4311-4316.

25. Yanagi, Y., A. Tishon, H. Lewicki, B. Cubitt, and M. B. A. Oldstone. 1992. Diversity of T-cell receptors in virus-specific cytotoxic T lymphocytes recognizing three distinct viral epitopes restricted by a single major histocompatibility complex molecule. J. Virol. 66:2527-2531.

26. Lewicki, H., T. McKee, A. Tishon, M. Salvato, J. L. Whitton, and M. B. A. Oldstone. 1992. Novel $\mathrm{H}-2^{\mathrm{k}}$ restricted CTL clones recognize internal viral gene products and cause CNS disease. J. Neuroimmunol. 41:15-20.

27. Maniatis, T., J. Sambrook, and E. F. Fritsch. 1990. Molecular Cloning: A Laboratory Manual. Nancy Ford and Chris Nolan, editors. Cold Spring Harbor Laboratory, Cold Spring Harbor, NY. 14.1-14.35.
28. Whitton, J. L. 1990. Lymphocytic choriomeningitis virus CTL. Seminars in Virology. 1:257-262.

29. Lee, M.-S., M. von Herrath, H. Reiser, M. B. A. Oldstone, and N. Sarvetnick. 1995. Sensitization to self (virus) antigen by in situ expression of murine interferon- $\gamma$. J. Clin. Invest. 95:486-492.

30. Gairin, J. E., and M. B. A. Oldstone. 1993. Virus and cytotoxic T lymphocytes. I. Crucial role of viral peptide secondary structure in MHC class I interactions. J. Virol. 67:2903-2907.

31. Baekkeskov, S., and B. Hansen. 1990. Human diabetes. Curr. Top. Microbiol. Immunol. 164:1-198.

32. Eisenbarth, G. S. 1986. Type 1 diabetes mellitus. A chronic autoimmune disease. N. Engl. J. Med. 314:1360-1368.

33. Ohashi, P., S. Oehen, P. Aichele, H. Pircher, B. Odermatt, P. Herrera, Y. Higuchi, K. Buerki, H. Hengartner, and R. M. Zinkernagel. 1993. Induction of diabetes is influenced by the infectious virus and local expression of MHC class I and tumor necrosis factor alpha. J. Immunol. 150:5185-5194.

34. Campbell, I., T. Kay, L. Oxbrow, and L. C. Harrison. 1991. Essential role for interferon-gamma and interleukin-6 in autoimmune insulin dependent diabetes in NOD/Wehi mice. J. Clin. Invest. 87:739-742.

35. Campbell, I., and L. C. Harrison. 1990. Molecular pathology of type I diabetes. Mol. Biol. \& Med. 7:299-309.

36. Fitch, F. W., M. McKisic, D. Lancki, and T. Gajewski. 1993. Differential regulation of murine T-lymphocyte subsets. Annu. Rev. Immunol. 11:29-48.

37. Modlin, R., and T. B. Nutman. 1993. Type 2 cytokines and negative immune regulation in human infections. Curr. Opin. Immunol. 5:511-517.

38. Harding, F. A., and J. P. Allison. 1993. CD28-B7 interactions allow the induction of $\mathrm{CD} 8+$ cytotoxic $\mathrm{T}$-lymphocytes in the absence of exogeneous help. J. Exp. Med. 177:1791-1796.

39. Sagerstrom, C. G., E. Kerr, J. P. Allison, and M. M. Davis. 1993. Activation and differentiation requirements of primary T-cells in vitro. Proc. Natl. Acad. Sci. USA. 90:8987-8991.

40. Sarvetnick, N., J. Shizuru, D. Liggitt, L. Martin, B. McIntyre, A. Gregory, T. Parslow, and T. Stewart. 1990. Loss of pancreatic islet tolerance induced by $\beta$-cell expression of interferon- $\gamma$. Nature (Lond.). 346:844-847.

41. Kuendig, T., A. Shahinian, K. Pfeffer, R. M. Zinkernagel, I. Horak, T. Mak, and P. S. Ohashi. 1994. Antiviral immune responses in IL-2 and CD28 deficient mice. J. Cell. Biochem. Suppl. 18D:429.(Abstr. V-715.)

42. von Herrath, M. G., J. Dockter, M. Nerenberg, J. E. Gairin, and M. B. A Oldstone. 1994. Thymic selection and adaptability of cytotoxic T lymphocyte responses in transgenic mice expressing a viral protein in the thymus. J. Exp. Med. 180:1901-1910.

43. Kasaian, M. T., and C. A. Biron. 1990. Effects of cyclosporin A on IL-2 production and lymphocyte proliferation during infection of mice with LCMV. J. Immunol. 144:299-306.

44. Kasaian, M. T., K. Leite-Morris, and C. Biron. 1991. The role of CD4+ cells in sustaining lymphocyte proliferation during LCMV infection. J. Immunol. 146:1955-1963.

45. Green, E. 1981. Breeding systems. In The Mouse in Biomedical Research. H. Foster, D. Small, and J. Fox, editors. Academic Press Inc., Harcourt Brace Jovanovich, Publishers, San Diego, CA. 91-110. 